Revista de la red interuniversitaria de estudios sobre las literaturas rioplatenses contemporáneas en Francia

$11 \mid 2014$

De niños e infancias

\title{
Infancias póstumas y el tiempo de l'Enfantin
}

\section{Victoria Liendo}

\section{OpenEdition}

\section{Journals}

Edición electrónica

URL: http://journals.openedition.org/lirico/1812

DOI: $10.4000 /$ lirico. 1812

ISSN: 2262-8339

Editor

Réseau interuniversitaire d'étude des littératures contemporaines du Río de la Plata

Referencia electrónica

Victoria Liendo, «Infancias póstumas y el tiempo de l'Enfantin », Cuadernos LIRICO [En línea], 11 | 2014

Puesto en línea el 01 diciembre 2014, consultado el 04 mayo 2019. URL : http://

journals.openedition.org/lirico/1812; DOI : 10.4000/lirico.1812

Este documento fue generado automáticamente el 4 mayo 2019.

\section{(c) $($ ) $(9)$}

Cuadernos LIRICO está distribuido bajo una Licencia Creative Commons Atribución-NoComercialSinDerivar 4.0 Internacional. 


\title{
Infancias póstumas y el tiempo de l'Enfantin
}

\author{
Victoria Liendo
}

1 Los relatos de infancia de Witold Gombrowicz nos llegan en forma póstuma o casi póstuma: por un lado Testament (1968), publicado un año antes de su muerte bajo la impronta oral de entrevistas que evocan un testamento leído en voz alta, con asma, antes de morir; por el otro, Recuerdos de Polonia (1977), una serie de conferencias radiales escritas entre 1959 y 1961 para la Radio Europe Libre de Munich que finalmente nunca saldrán al aire y quedarán encajonadas hasta 1976 cuando su mujer Rita encuentra el manuscrito entre sus papeles.

2 De los relatos de infancia de Victoria Ocampo habría que distinguir entre los que se cuelan, aleatorios, en numerosas de sus intervenciones escritas en la revista SUR y los propiamente dichos, los que constituyen un pequeño proyecto literario, carozo de $\mathrm{El}$ archipiélago (1979), primer tomo de su autobiografía publicado el mismo año de su muerte.

El azar de que ambos autores inscriban sus recuerdos de infancia como una suerte de epílogo a su trayectoria literaria resulta significativo para los propósitos de este trabajo : me propongo rastrear en la obra de uno y otro, a partir de los relatos recobrados, la presencia del niño que supieron ser. En particular, busco en el niño la presencia de un tiempo, el de 'l'Enfantin', concepto que Pierre Péju introduce y desarrolla minuciosamente en su teoría de la infancia.

4 Enfance Obscure (2011) comienza por distinguir l'Enfantin del recuerdo de infancia en tanto que maneja una relación distinta con el tiempo y con el relato : son bloques de percepción desprendidos de sus fechas y contextos que, no habiendo encontrado todavía su expresión, sobreviven dormidos en alguna parte de nuestra memoria. Que no se integren a ninguna cronología y escapen a la estructura edípica de los recuerdos encubridores les asigna la marca de una temporalidad de otro orden: abierta, sincrónica, fugaz, mancomunada, ajena e íntima a la vez, familiar y extraña. El tiempo de l'Enfantin es la convivencia del pasado y el presente en un instante fugitivo y actual que señala un más allá, un gran Afuera, y un antes de acá, el tiempo de los niños y los muertos. En este 
sentido, se emparenta a lo que Deleuze llamó "bloc d'enfance" ("ce n'est pas l'enfant devant l'adulte, ni la mère avant l'enfant ; il est la stricte contemporanéité de l'enfant et de l'adulte") y lo que Bachelard nombró "noyau d'enfance" ("ce passé mort [celui de l'enfance] a en nous un avenir, l'avenir de toutes ses images vivantes"). "D'ailleurs, lorsqu'il survient, de façon aléatoire, il résulte autant de la mémoire que de l'imagination. Il appartient autant au passé qu'à l'actuel" (Péju, $2011: 65$ ).

¿Cómo y cuándo se manifiesta l'Enfantin? De naturaleza accidental, azarosa, lejos de ser una cuestión de memoria, se trata del descubrimiento de "une perception actuelle qui se double, sans qu'on y prenne garde, d'une autre perception" (Péju, 2011, 26). Son "perceptions fantômes, en vrac, qui remontent à "quand j'étais petit " -pero "ne coïncide[nt] pas avec "qui je fus »" (Péjou : 2011, 54) - : "elles dormaient dans ma chair mentale, et voilà qu'elles s'éveillent, intactes, toujours vivaces" (Péju : 2011, 16). "La chair mentale" remite a una participación esencial de l'Enfantin, a saber, el cuerpo y su memoria, la sensación brumosa de un descubrimiento infantil -nunca formulada, nunca dicha- que puede alojarse secretamente en el gesto de una mano, en una imagen, en el fondo de un cuadro o en una melodía.

6 L'Enfantin y el cuerpo están unidos también en la forma física que toma la sensibilidad infantil : la mirada metonímica del mundo, hipnótica frente al detalle, la amplificación de lo espeluznante, mezcla de fascinación y miedo, el registro silencioso de sensaciones que no encuentran interlocutor ni duración en la consciencia pero dejan una huella profunda (Péju : 2011, 17). Quizá lo más importante sea decir estas percepciones en espera, "non pas refoulé mais inemployé" (Péjou: 2011, 65), acechan, por así decirlo, el momento de la escritura porque es sólo ahí donde, de manera fragmentada y en desorden, logran encontrar un lenguaje que les dé expresión. L'Enfantin es, entonces, un tiempo hecho de tres tiempos: el de la percepción tácita del niño, el de la actualización misteriosa en el adulto y el de la escritura, donde se manifiesta.

7 Si las ficciones de infancia estructuran las ficciones de autor, como Molloy (1996) ya ha demostrado, si, reformulando el famoso verso de Wordsworth, el Niño es el padre del Autor, ¿qué relación podríamos establecer entre l'Enfantin y el Yo que en los textos dice Yo ? El objetivo de este artículo es, como primer paso, encontrar el tiempo de l'Enfantin en la obra de Gombrowicz y Ocampo a partir de un cotejo entre sus recuerdos de infancia póstumos y los textos publicados en vida. El segundo paso será preguntarnos qué función cumple l'Enfantin en estos textos, de qué habla, qué devela : qué es.

\title{
Un grillo para franquear el tiempo
}

\author{
¡Para qué sirve inventar! \\ Lo cierto es más raro. \\ SILVINA OCAMPO, Invenciones del recuerdo
}

8 En 1952, año en que empieza a escribir su autobiografía, Victoria Ocampo viaja a Alemania. Ya había estado allí en 1930, en Berlín, en compañía de Drieu La Rochelle y en 1946, en Nüremberg, para los juicios. Seis años después Berlín sigue destruida como si la guerra recién hubiera terminado. Ella la recorre en el auto de un Ministro que le va mostrando los restos de la ciudad. Está sola. Tiene 62 años. De golpe, Ocampo siente el canto de un grillo que no está en la escena en el momento de la narración sino en su memoria, aislado, autónomo, un grillo que supo estar en el mismo lugar que esas ruinas habían borrado veintidós años antes, en el viaje de seducción y conflicto que la unió a La 
Rochelle. ¿Por qué recuerdo ahora aquel grillo de Tier Garden, el día del regreso de Drieu a París? ¿Y los recuerdos que ese grillo desencadenó ?"(Ocampo : 1979, 53), Ocampo se extiende sobre aquello que ignora, que se le escapa, la arbitrariedad de un recuerdo que mezclándose con otros forma una constelación de imágenes y sensaciones fusionados por el mérito de un solo sonido salvaje. Es un instante de "soledad sonora", tiempo en el que suena una ausencia que se convierte, paradójicamente, en el detalle crucial del presente. Es allí donde reverbera l'Enfantin, como si la escena fuese una fotografía y el canto invisible del grillo el "punctum","pinchazo, agujerito, pequeña mancha, pequeño corte, y también casualidad", "azar en que [la foto] me despunta (pero también me lastima, me punza)" (Barthes : 2005, 59).

9 El grillo berlinés de 1930 que estando "en una atmósfera de invernadero se figuraba, el pobre, que era pleno verano" (Ocampo: 1979, 53) es la metáfora del mismo proceso que atraviesa la que escribe al oírlo cantar: en un "Berlín macizo, imponente, sin gracia, hecho migajas", ella se encuentra de golpe horadada por el recuerdo de un verano porteño que se astilla en diferentes tiempos, el de sus veinte años y el de su niñez: "el ruido estridente, $\tan$ familiar" la "traspasa", la "transporta, vertiginosamente, a los días calurosos de Villa Ocampo, al instante jamás perdido y tan a menudo repetido", en que se miraba por última vez al espejo antes de salir al encuentro furtivo de su amante Julián Martínez, primo de su marido, "en una calle fea de un barrio feo". Pero la estela del sonido no termina ahí. La cadena de asociación libre que dispara el grillo empieza en 1952, cuando ya tanto Drieu como Julián están muertos, se instala luego en 1930, el día en que Ocampo se despide de su amante actual (Drieu) emocionada por el recuerdo del anterior (Julián) y aterriza por virtud de "la linterna mágica de los sonidos" en el "balbuceo" de su hermana Angélica a la hora de recitar la fábula de Florian,"Le grillon". Grillo de ficción y grillos de la vida se confunden como en la escritura de Ocampo se funden literatura y experiencia : ahí veía Molloy al cuerpo ${ }^{1}$, ahí vemos nosotros l'Enfantin. Ya no se trata solamente de una "presencia en escena" sino de la presencia de un cuerpo capaz de subvertir las fronteras temporales en el espacio de un cri-cri :

Qu'est-ce que l'Enfantin? C'est la nudité soudaine, le brusque abandon à l'instant présent, l'attention hypnotique à un détail, le changement du regard sur ce qui m'entoure, l'inexplicable nouveauté d'un geste, le détournement provisoire de l'usage des objets. (Péju : 2011, 54)

10 L'Enfantin irrumpe, se ajusta al relato autobiográfico y lo sobrepasa, lo mezcla, lo suelda en una sola pieza imposible de deglutir para una inteligencia sin cuerpo, para un genio sin carne.

¡Que un grillo pueda romper así los diques del tiempo y mezclar pasado y presente, resucitar recuerdos sin ojos, sin voces, sin bocas y probarnos que no hay compartimentos estanco más que en el estrecho desfiladero de la inteligencia! (Ocampo : 1984, 54)

11 La lección de francés que la hermana menor aprende empezaba "cuando hacía más calor en San Isidro y la acompañaban el canto de los grillos y las cigarras" mientras que Victoria "esperaba el momento de soplarle el verso siguiente que ella olvidaba... 'Caché dans l'herbe fleurie... heu... heu'"(Ocampo : 1984, 55). El olvido de Angélica la expone a un olvido propio : la estrofa que reproduce ("Un pauvre petit grillon /caché dans la fleurie/ regardait un papillon/s'ébattre dans la prairie") es incorrecta. "Pero "s'ébattre no era el verbo. ¿Cuál era entonces? ¿Qué hacía la mariposa en la pradera de mis nueve años ?" (Ocampo: 1984, 55). La búsqueda del verbo olvidado "como un calambre (físico)" la distrae de su "pena (moral)" y de la "crisis de nostalgia fulgurante" (Ocampo : 1984, 55). El 
cuerpo de la niña que hace trampa, el de la amante que se mira en el espejo antes de salir a esconderse en barrios feos y se despide de hombres difíciles en ciudades europeas resuenan en el cuerpo acalambrado de la mujer mayor que olvida un verbo de su infancia en medio de una Berlín devastada. Esta sincronía física (que el calambre traduce) se activa, interviene en busca del verbo perdido, se expande en el misterio del lenguaje y vuelve trivial el sentimiento nostálgico, organizado, "(moral)".

El recuerdo de infancia queda desplazado por la inquietud de la palabra ausente, palabra a la que, sin nunca reponerla, su propia digresión deja atrás. Pero, como en la carta robada, el secreto no está en lo que falta sino en lo que está delante de nuestros ojos. Del misterio que "s'ébattre" parecía enmascarar, pasa en cambio a recordar la moraleja : "Pour vivre heureux, vivons caché". Se indigna entonces y cede en su prosa a la indignación : ¿por qué la mariposa es castigada por "revolotear" entre las flores y el grillo se salva por no dejarse ver?

El verbo del original es "voltiger" que significa lo mismo que "s'ébattre" (revolotear), salvo que el segundo tiene además una connotación sexual considerable. A eso se suma el efecto sonoro del significante : "S'ébattre" evoca "se battre", pliegue primero de la autofiguración de Ocampo, a saber, la niña que se enfurece frente a la injusticia, frente al sometimiento de la libertad individual y frente a las reglas obsoletas de una sociedad oligarca. El primer recuerdo que narra El archipiélago es una escena de sorpresa, miedo e indignación, mezcla infantil de la que subraya : "La indignación sobre todo me ahogaba" (Ocampo : 1979,75). Lo mismo hace en el segundo y en muchos otros. La batalla en voz alta y la transgresión en secreto, a escondidas, forman el estilo de vida y de escritura de Ocampo. La batalla contra los suyos y contra sí misma, contra su bilingüismo y su vocación de hija se lleva a cabo a través de una escritura que constantemente se define como indigna ("una pordiosera de las letras" se autoproclama, para dar un ejemplo, en el prefacio a la nueva edición de su primer libro en 1962). La lucha feminista por su expresión individual a partir de la cual pulsa su voluntad de escribir deja traslucirse otra lucha más interna y más misteriosa: "Toute création est un combat entre une langue apprise et cette langue bredouillée et malhabile de l'Enfantin". Victoria, como el grillo de Florian, camufla su deseo de escritura en una vida oculta, que lee, reescribe y actúa : ahí reside su estilo, su obra más remarcable.

"Veintidós años después de este minuto, el grillo del Tier Garten - mientras el fondo de mí había atravesado hecatombes públicas y privadas- permanecía intacto en mi memoria elefantina." (Ocampo : 1984, 55). Es la sincronía de tiempos que estalla en la escritura lo que permanece intacto en su memoria "elefantina" y "enfantine", allí donde impera su "génie charnel", como Drieu lo supo a llamar.

\title{
La vergüenza original
}

\author{
Era como si la vergüenza \\ debiera sobrevivirlo. \\ FRANZ KAFKA, El Proceso
}

La literatura de Gombrowicz, como las grandes literaturas, es la repetición innovadora de dos o tres ideas. Mitos, los llama él : la "cuculisation" y "la gueule", que en Buenos Aires del ' 47 los legendarios muchachos del café Rex tradujeron como "facha". La juventud, concepto nuclear en Gombrowicz, es la cifra metafórica de su teoría de la Forma. Todo 
ronda alrededor de un mismo eje : cuculizar a alguien es infantilizarlo, la facha es la deformación de sí que todo hombre padece frente a cualquier otro, cretino o no, y la juventud es el elogio (el refugio, la defensa y el contra-ataque) de la forma inacabada, de lo inmaduro, de lo que respira y se funda en el tiempo de la transformación justo antes de que acuñe una forma fija. Las tres metáforas se fundan en un elemento en común: la humillación. A veces vergüenza, a veces asco, a veces pavor: la percepción de una desigualdad brutal, desgarradora, y el consecuente posicionamiento del lado de "lo inferior" es el motor del absurdo, la pantomima decadente y la enunciación barroca que generan las ficciones de Gombrowicz.

¿Qué representa, por dar un ejemplo clave, "Retiro" en la obra de Gombrowicz? Un proceso similar al de la cristalización stendhaliana : un lugar marginal, lumpen, se vuelve diamante ante los ojos de Gombrowicz por parecerle "inaccesible" en su homogeneidad (la del marinero, la del soldado); se convierte, así, en su único punto de referencia, el sustituto de todos aquellos que había ido perdiendo en el camino : "[Retiro] no tardó en aparecérseme como el único, máximo y absoluto valor de la vida y como la única belleza" (Gombrowicz, 197) ; "y ésta era mi nueva patria, con la que poco a poco iba sustituyendo a la anterior" (Gombrowicz, 196). Pero algo de la anterior como de ésta, quizá no por azar, cristaliza una relación atravesada por el elemento vergonzoso, humillación de la que pareciera no puede escapar :

Sin embargo, este valor tenía una característica inventada probablemente por el mismísimo diablo, y que consistía en que, siendo juventud, era algo que estaba siempre por debajo del valor, algo estrechamente ligado a la humillación, era la humillación misma. (Gombrowicz, 197).

17 ¿Hay un origen para este rasgo ineludible y fundamental ? L'Enfantin, como habíamos visto, podía partir de una amalgama de sensaciones del género: “Car l'Enfantin n'est jamais séparable d'une menace, de l'expérience originelle d'une peur, d'une honte ou d'un enchantement. Des recoins sombres d'où la monstruosité, croit-on, va surgir" (Péju : 2011, 20. Las cursivas son nuestras). ¿Dónde está, cuál es el comienzo de esta vergüenza?

Los recuerdos de infancia, tanto en Testament como en Recuerdos de Polonia, recuperan un origen poco creíble para los contemporáneos del escritor polaco exiliado en Argentina. Familia noble, terrateniente, padre aristócrata lituano y madre adinerada polaca, dos hermanos mayores, una hermana menor, la mansión del campo y una tropa de criados son el negativo de su personaje mitómano, autoproclamado conde excéntrico de un oriente desconocido para las orillas del Plata. Similar al sistema de privilegios y educación que leemos en la infancia de Ocampo, el ambiente familiar y su pertenencia de clase desarreglan los sentidos del niño Witold. Es ahí donde comienzan sus sufrimientos infantiles y con ellos su arte.

19 La percepción infantil queda para siempre marcada por la disonancia dolorosa de dos posturas, ideas, valores opuestos funcionando simultáneos como si fueran uno. ¿Es lituano o polaco? ¿Es acaso un verdadero aristócrata, "racé" como su padre, o un noble decadente devenido en tilingo, "inconséquent", como su madre? ¿Son terratenientes o son industriales? "Ce ne sont là que les premiers de ces "entre" qui par la suite se multiplieront au point de presque devenir ma résidence, ma vraie patrie" (Gombrowicz: 1996, 9). Esta condición de "entre" con la que se identifica al punto de vislumbrarla como una forma del destino (que lleva a cabo), tiene su primer origen, antes de manifestarse en la percepción de espacios distintos y clases sociales jerárquicas, en el gobierno interno de su madre. Ahí reside la disonancia original : una mujer que creía ser todo menos lo que 
era ("Elle n'était qu'admiration pour tout ce qu'elle n'était pas"), una mujer "irreal", como dirá Gombrowicz, que se presenta frente al niño como un absurdo de carne y hueso que lo asusta, lo avergüenza y, sobre todo, lo dispone al combate. Amenazado por la incongruencia espeluznante de la figura materna, el niño entra en un juego de provocaciones y diálogos sin sentido. Esta práctica depara dos consecuencias : por un lado, "su primera iniciación al arte" (“C'est elle qui m’a poussé dans le pur non-sens, dans l'absurde, devenu plus tard l'un des éléments les plus importants de mon art" (Gombrowicz : 1996, 11) ; por el otro, la fidelidad al patrón del oxímoron, a la dicotomía férrea, a la figura del "entre" que, descolocado frente a bifurcación de dos opuestos, abraza el margen.

La duplicidad intrínseca de la madre se proyecta creativamente en nuevas formas e imágenes : padre-madre, oriente-occidente, amo-esclavo, real-irreal, maduro-inmaduro por nombrar algunas. La más patente en los relatos de infancia es la que cristaliza la figura del criado: "La plus grande honte de ma famille: "Les domestiques! Les domestiques!" (Gombrowicz : 1996, 13). La humillación, pivote de la diferencia de clase, lo destierra a una percepción extrañada de los suyos. Frente a dos modelos radicalmente opuestos de gestualidad, vestimenta, discurso y hábitos, la mirada lúcida del niño descubre la mentira del adulto: la afectación de las formas nobles, particularmente vigentes en la anacrónica Polonia de entreguerras, le parecen "un phénomène grotesque et absurde, stupide, douloureusement comique et même répugnant" (Gombrowicz : 2003, 22). La desigualdad social, de esta forma, se traduce para el niño en una decisión estética, por un lado, y en un posicionamiento ético, por el otro : para siempre quedará enamorado de la belleza de los pies descalzos y las camisas de escarza del peón quien, a pesar de esta "admiration furtive, soigneusement masquée", representa un ideal inaccesible para él, señorito noble de campo, al que tener que usar botas de goma y responder a las órdenes de la gouvernante francesa lo "precipitan en un abismo de humillación".

21 L'Enfantin se apropia de una definición de Deleuze que dice "c'est la vraie vie de l'enfant": aquello que sobrevive en nosotros sin un lenguaje certero, ¿no es acaso nuestra marca más cierta? El niño Witold y su infancia avergonzada reverbera en "los destellos" de Retiro, en "el secreto de esa vida floreciente y a la vez humillada" (Gombrowicz, 196) así como "en sus [mis] recuerdos, todos aquellos días de su [mi] existencia cotidiana en Buenos Aires están forrados de la noche de Retiro" (Gombrowicz, 196). No es extraño que sea en el tiempo de la escritura donde estas dos humillaciones (que son a la vez contrarias y a la vez la misma) encuentren una síntesis: "ahogado de sibaritismo", el joven Gombrowicz se va solo con dos criados a una casa de campo a escribir sus primeros relatos. Únicamente el oficio de escritor y la ingrata práctica de la escritura le permitirán hacer una experiencia de la vergüenza que lo acosa tanto y cuanto lo fascina :

Je travaillais si dur qu'un cocher ou un cuisiner, ce qui soulageait ma conscience -et pourtant ce travail demeurait malgré tout vaguement suspect, comme s'il reposait sur un mensonge... C'est alors que je connus pour la première fois la honte qui accompagne tout travail artistique. (Gombrowicz : 2003, 71-72).

\section{Dime cuál es tu Enfantin y yo te diré cuál es tu estilo}

Car il faut que par une dialectique retorse il y ait dans le Texte, destructeur de tout sujet, un sujet à aimer, ce sujet est dispersé, un peu comme les cendres que 


\section{l'on jette au vent après la mort. ROLAND BARTHES, Sade, Fourier, Loyola} cuerpo, la escritura y el estilo? ¿Podemos acaso pensar al estilo como la presencia de un cuerpo en la escritura? ¿Podemos concebir la forma en que se escribe como una forma de caminar, de caer o de estornudar? ¿Hay en la escritura un cuerpo en movimiento ? Sylvia Molloy lee en la obra de Ocampo la aparición de un cuerpo en escena : un cuerpo teatral surge en sus textos mostrando lo que la sociedad buscaba reprimir. La teatralidad no escapa tampoco a Gombrowicz, ni en sus ficciones ni en sus textos autobiográficos donde su Yo gesticula y ensaya poses como un actor comprometido con una obra que no se terminó de escribir. Como lo hemos visto, la relación con un cuerpo adulto en movimiento resulta de la memoria del cuerpo enfantin. En efecto, l'Enfantin de Péju señala una relación entre lo inarticulado que descansa en la memoria de un individuo y las contorsiones que su cuerpo adopta frente a la misteriosa memoria de los sentidos: "C'est à partir de telles contractions d'images, de telles réactions nerveuses et musculaires, que nous devenons ce que nous sommes, que notre âme s'infléchit et que notre créativité trouve sa puissance. (...) « Dis-moi quel est ton Enfantin, et je te dirai...» Quoi ? Quel est ton style. Quelle est ta fêlure" (Péju : 2011, 27). Para Péju, el estilo no sería entonces una manera sino la expresión de una fisura, fractura o rasguño que estarían señalando ya no solamente un cuerpo sino el inconsciente de ese cuerpo, su memoria y sus propias asociaciones de sentido. Ahí radicaría el estilo, en estricta relación con l'Enfantin. qu'on appelle l'écriture - c'est-à-dire le travail du corps qui est en proie au langage passe par le style" (Barthes: 1981, 190). En sus últimos textos, Barthes bosqueja la presencia de un cuerpo para hablar de la escritura. Las formas sugestivas del escritor francés no explican en el contexto de esta entrevista menor al final de su carrera de qué tipo de cuerpo de se trata o a qué llama él "cuerpo". Le queda al lector construir una glosa para entender esta cita. Podríamos decir : un cuerpo surge del lenguaje, sobrepasándolo; está en su origen pero es también su consecuencia. Como si fuera raptado por el lenguaje (toda presa implica un depredador), es un cuerpo que trabaja su rapto, que se contorsiona y encuentra su existencia o su materia en el misterio del lenguaje escrito. Más puntualmente, como si la minuciosa conceptualización que Barthes ha hecho a lo largo de su obra acerca de la noción de "escritura" pudiera suspenderse en el espacio de lo actual bajo la fuerza del "malgré tout", Barthes anuncia sin reticencias ni matices que toda escritura pasa por el estilo : "L'écriture commence même par le style, qui n'est pas le bienécrire : il se reflète au profond du corps, et ne peut être réduit à une intention de joliesse petitement esthétique" (Barthes : 1981, 190). El estilo ya no es decorativo, no mantiene una relación con el adorno estrictamente estético ni se preocupa por la forma sino que es la manifestación de un fondo : no señala el adorno de una sintaxis sino lo profundo de ese cuerpo que, una vez que el lenguaje lo apresa, se trabaja a sí mismo en la escritura, escribiéndose.

Este enfoque que relaciona al estilo con una idea de cuerpo nos reenvía a un primer período de su obra, es decir, a las postulaciones que ya en Le degré zéro de l'écriture (1953) concebían al estilo como un léxico íntimo que nacía del cuerpo y del pasado del escritor ("des images, un débit, un lexique naissent du corps et du passé de l'écrivain et deviennent peu à peu les automatismes mêmes de son art"), un lenguaje autárquico, inmanente y privado, "qui ne plonge que dans la mythologie personnelle et secrète de l'auteur 
(...) où se forme le premier couple des mots et des choses, où s'installent une fois pour toutes les grands thèmes verbaux de son existente". El estilo es para el joven estructuralista de los años cincuenta "une démarche close de la personne", un secreto o un recuerdo encerrado en el cuerpo del escritor, es "la cosa" del escritor, "su prisión y su esplendor, su soledad”. Esta definición de estilo barthesiano se acerca pertinentemente a la noción aquí estudiada de Péju.

L'Enfantin, tiempo donde pulsa el estilo y la fisura singular de cada uno, tiempo de la escritura, del cuerpo y la imaginación, es en Gombrowicz esa vergüenza original que estalla en literatura : el niño frente a su madre es el primer cuculizador, tan despiadado como Polilla frente a las orejas de Sifón, como Filip enloqueciendo a su mujer con su criada Czesia, como Ignacy "bameando" con una carcajada a su padre Tomasz : "C'est sans un brin de pitié, sans amour, plein d'une ironie glacée, que j'ai mené mon jeu avec elle, plusieurs années durant. Elle m'aimait beaucoup." (Gombrowicz, 1996: 13). El estilo de Ocampo, en cambio, se nutre del preciso hecho de que nunca haya escrito ficción. Sin haber nunca logrado (nunca sabido o nunca deseado) desembarazarse de su yo, la escritura de Ocampo adopta un rasgo clásico, cuidado, casi defensivo, que acompaña con una postura de precariedad frente a la escritura : es la "pordiosera de las letras" ${ }^{2}$ que le agradece un prólogo a Ortega y Gasset, la mujer sin credenciales literarias que escribe para un "lector perezoso", la "autodidacta"4 que no le escatimará la menor de sus "malandanzas". Es la rebeldía en una forma clásica, la compostura y la implosión, la fuga de rupturas nunca hechas a través de los infinitos recovecos del lenguaje, de la música, de los objetos, de los nombres, de las citas.

Las infancias póstumas de Gombrowicz y de Ocampo nos descubren los rastros de l'Enfantin; nos permiten reconstruir esa temporalidad otra irrumpiendo y recorriendo diferentes lugares de sus obras ; nos devuelven algo de sus cuerpos y una pista arriesgada sobre el origen de sus estilos. Más importante aún, estos relatos nos proponen pensar un más allá del epílogo y un más acá del comienzo. Son algo más que la sorpresiva nota final en la historia de una vida o la esperada versión retrospectiva de su principio : representan una fisura en el sistema narrativo (orgánico o no) del Yo, una laguna jurídica en las leyes del tiempo y el relato, inoculando en el lector una sospecha : ¿no es acaso la infancia en sí misma siempre un relato póstumo? ¿No señala lo póstumo algo tan imposible de recuperar como los eventos que eclipsa el recuerdo encubridor ? ¿No es la infancia como un muerto que habla con las palabras de alguien que todavía no nació ?

\section{BIBLIOGRAFÍA}

Barthes, Roland. Le degré zéro de l'écriture (1953) dans Euvres complètes, vol. 1. Paris : Seuil, 1972.

Barthes, Roland. Sade, Fourier, Loyola. Paris : Seuil, 1971.

Barthes, Roland. Le grain de la voix. Paris : Seuil, 1981.

Gombrowicz, Witold. Ferdydurke. Buenos Aires, Sudamericana, 1964.

Gombrowicz, Witold. Bakaki. Barcelona : Tusquets, 1986. 
Gombrowicz, Witold. Diario. Madrid : Seix Barral, 2010.

Gombrowicz, Witold. Souvenirs de Pologne. Paris : Gallimard, 2003.

Gombrowicz, Witold. Testament. Paris : Gallimard, 1996.

Péju, Pierre. Enfance Obscure. Paris : Gallimard, 2011.

Ocampo, Victoria. El archipiélago. Buenos Aires : SUR, 1979.

Ocampo, Victoria. De Francesca a Beatrice. Buenos Aires : SUR, 1951.

Ocampo, Victoria. Testimonios, Series primera a quinta. Buenos Aires : Sudamericana, 1999.

\section{NOTAS}

1. "Veo esas referencias al cuerpo como algo significativamente más complejo, algo que sin duda incluye lo concretamente físico pero que va más allá, más bien como una presencia (como se habla de presencia en escena) que la sociedad intentaba reprimir y de la cual su cuerpo era su signo más visible" (Molloy : 1996, 98).

2. Así se define en el prólogo a la nueva edición de su primer libro De Francesca a Beatrice, Buenos Aires, SUR, 1951.

3. Ibidem.

4. V. Ocampo, "Malandanzas de una autodidacta" en Testimonios, Series primera a quinta, Buenos Aires, Sudamericana, 1999.

5. Ibidem.

\section{RESÚMENES}

¿La infancia no es acaso siempre un relato póstumo ? Este trabajo nos propone pensar la infancia como un origen que se resiste a identificarse con el principio de una vida. Por el contrario, se trata de un tiempo primordial que nunca deja de suceder, que irrumpe y subvierte la linealidad a la que aspira el género autobiográfico. En la memoria del cuerpo se alojan ciertas percepciones infantiles que, sin haber sido todavía articuladas en palabras, encuentran su expresión repentina y aleatoria en la escritura. A partir de la noción de "l'Enfantin" de Pierre Péju, el análisis comparativo de los relatos de infancia póstumos de Witold Gombrowicz y de Victoria Ocampo nos develan la coexistencia de diferentes tiempos en una misma primera persona, los rastros de un cuerpo memorioso y una arriesgada pista sobre el origen de sus estilos.

L'enfance n'est-elle pas toujours un récit posthume? Ce travail propose de penser l'enfance comme une origine qui se refuse à être identifiée au début d'une vie. Il s'agit, au contraire, d'un temps primordial qui se produit sans cesse, fait irruption et subvertit la linéarité à laquelle aspire le genre autobiographique. Certaines perceptions infantiles, logées dans la mémoire du corps et jamais encore articulées, trouvent leur expression soudaine et aléatoire dans l'écriture. A partir de la notion d' " enfantin » de Pierre Péju, l'analyse comparative des récits d'enfance posthumes de Witold Gombrowicz et de Victoria Ocampo nous révèle la coexistence de différentes 
temporalités chez une même personne, les traces d'un corps chargé de mémoire et ouvre une piste concernant l'origine de leurs styles.

Isn't childhood always a posthumous tale? This work approaches childhood as an origin that refuses to be identified with the beginning of a life. On the contrary, it is a primeval moment that never fails to happen, subverting the linearity of time to which autobiography usually tends. The body has a memory, and houses infantile perceptions that haven't yet been articulated in word. They later find a sudden random expression in writing. From Péju's notion of l'Enfantin, the comparative study of Witold Gombrowicz's and Victoria Ocampo's childhood stories reveals the coexistence of different temporalities in one same first person, the traces of a memorial body and a risky hint of their styles' origin.

ÍNDICE

Mots-clés: enfance, posthume, Enfantin, corps, style

Keywords: childhood, posthumous, body

Palabras claves: infancia, lo póstumo, cuerpo, estilo

\section{AUTOR}

VICTORIA LIENDO

Université Paris 8- Université Paris-Est Créteil Val-de-Marne 